\title{
Contribution to The Performance of Mobile Radio Systems by Optimizing The Okumura Hata Model by Linear Regression: Application to The City of Annaba in Algeria
}

\author{
Riad Saidi $^{1}$, Lamir Saidi ${ }^{2}$, and Zine el abidine Regai ${ }^{3}$ \\ LAAAS Laboratory, Universty Batna 2, Batna, 05000 Algeria \\ ${ }^{1}$ riadsaidi5@gmail.com, ${ }^{2}$ lamir_saidi@yahoo.fr, ${ }^{3}$ zizou33@gmail.com
}

\begin{abstract}
The study of propagation characteristics is a fundamental step in mobile radio engineering; which is intended to achieve maximum performance for a mobile radio system. To do this, the propagation models are essential tools for this study such as the evaluation of the signal strength received by a mobile terminal, the evaluation of coverage radii and deduce the number of cells needed to cover a given area, such as radio planning, which in turn is the step that aims to estimate the necessary equipment and configurations of the radio interface. In this work we adopt the standard $\mathrm{K}$ factor model and OKUMURA HATA model to demonstrate a propagation model adapted to the physical environment of the city of Annaba in Algeria using a linear regression algorithm based on the ordinary least squares method. Radio measurements were carried out on the CDMA network of operator Mobilis. The calculation of the square root of the mean square error between the actual data and the radio measurements and the prediction data derived from the model implemented allowing the validation of the results obtained. A comparative study between the value of the RMSE obtained by the new model and those obtained by the models $\mathrm{K}$ standard factors and the model of OKUMURA HATA allows us to conclude that the new model is better adapted to our local environment than that of OKUMURA HATA. The new model obtained can help increase the performance of mobile radio systems deployed in our territory.
\end{abstract}

Keywords: Model K factor, Model of OKUMURA HATA Linear regression.

\section{Introduction}

To obtain a propagation model that accurately reflects propagation characteristics radio in a given environment. It is necessary to rely on network coverage, the capacity of the network as well as the quality of service of it which are the essential points of a network planning. In order to have access to all the services offered by a network, it is necessary to give particular importance to the dimensioning of the latter. The use of propagation models is very widespread for the planning and installation of networks or also for the extensions of already existing networks, especially in the new towns. Contributing to the improvement of the performance of mobile radio systems. To determine the characteristics of the radio propagation channel, the tests of the concrete propagation modes and the calibration of the existing models are essential to have a propagation models that accurately represent the radio propagation characteristics of the environment being studied. Several types of software allow the improvement of the performance of mobile radio systems through the planning and sizing of mobile networks including prediction models namely: ASSET of AIRCOM company in England, Atoll of the French company FORK ... etc.

Some authors investigate the calibration of propagation models, Like Chhaya Dalila, and Garlic [1] who have studied « tuning of Cost231 Hata modle for radio wave propagation prédiction », Medeisis and Kajackas [2] who presented «the tuned Okumura Hata model in urban and rural zones at Lituania at 160, 450, 900 and $1800 \mathrm{MHz}$ bands », Prasad and al [3] have worked on « tuning of COST-231 Hata model based on various data sets generated over various régions of India », Mardeni \&Priya [4] have presented « optimized COST-23 I Hata model to predict path loss for suburban and open urbun environments in the $2360-2390 \mathrm{MH}$,

Received: June $25^{\text {th }}, 2017$. Accepted: December $26^{\text {th }}, 2017$

DOI: 10.15676/ijeei.2017.9.4.3 
Some authors have been particularly interested in the use of the least squares method to calibrate or determine the propagation models we have for example: Mingjing Yang and al [5] In China presented «A Linear Least Square Method of Propagation Model Tuning for 3G Radio Network Planning », Chen, Y.H. and Hsieh, K.L [6] TAIWAN presented «A Dual Least-Square Approach of Tuning Optimal Propagation Model for existing 3G Radio Network », Simi I.S andt ail [7] In Serbia presented « Minimax LS algorithm for automatic propagation model tuning », Allant Mousa, Yousef Dama and Ail [8] In Palestine presented «Optimizing Outdoor Propagation Model based on Measurements for Multiple RF Cell », Deussom Djomadji Eric Michel and Tonye Emmanuel [9] In cameroon have presented « Optimisation du modèle d'Okumura Hata par la régression linéaire. Application à la ville de Yaoundé au Cameroun», Famoriji and Olasoji[10] have presented «Development of a Radiowave Propagation Model for Hilly Areas», V.S. Abhayawardhana, I.J. Wassell, D. Crosby, M.P. Sellars, M.G. Brown[11] Who presented «Comparison of empirical propagation path loss models for fixed wireless access systems».

In our work, we used data collected from the network of operator Mobils. And this in the city of Annaba. To carry out this task we use 6 BTS distributed on both sides in the city. We also use an algorithm based on linear regression to determine a propagation model adapted to the city of Annaba.

This article will be articulated as follows: In the first part, we present the experimental details, followed by a description of the methodology chosen in the second part, the implementation of the algorithm as well as the results, their validations and comments will be addressed In the last part; At the end a conclusion will be presented.

\section{Experimental parts}

\section{A. Propagation environment}

The city on which our study was based is that of Annaba. We have emphasized the existing network to carry out radio measurements in this city. To do this, We subdivided the city into 3 zones: The city center of Annaba, the downtown area towards the outskirts and finally the outskirts of the city. For each type of zone, we used 2 similar types of environment.

Table 1. The zone

\begin{tabular}{|c|c|c|c|}
\hline Zone & Z1 & Z2 & Z3 \\
\hline Type of zone & Urbain & Suburbain & Rurel \\
\hline BTS planted & $\begin{array}{c}\text { Annaba center et Post } \\
\text { office befor Harbor }\end{array}$ & $\begin{array}{c}\text { Sidi Ammar et Sidi Ammar } \\
\text { center }\end{array}$ & $\begin{array}{c}\text { Airport Rabeh BETATE } \\
\text { Annaba }\end{array}$ \\
\hline
\end{tabular}

\section{B. Simplified description of the BTS used}

The BTS we used for our radio measurements are those of the state operator Mobils, We used 3 types of BTS namely the BTS types 3900 and 2206. The radio parameters of the BTS used are shown in the table below [12]:

Table 2. Characteristics of the BTS used

\begin{tabular}{|c|c|c|}
\hline & BTS3900 & BTS2206 \\
\hline Type of BTS & Outdoor Distributed & Outdoor Distributed \\
\hline Number of Sectors & 3 & 3 \\
\hline Frequency band & $806-960 \mathrm{MHz}$ & $806-960 \mathrm{MHz}$ \\
\hline Fréquency download & $880-960 \mathrm{MHz}$ & $880-960 \mathrm{MHz}$ \\
\hline Fréquency upload & $806-880 \mathrm{MHz}$ & $806-880 \mathrm{MHz}$ \\
\hline Total power of the BTS & 600 Watt (at $50{ }^{\circ} \mathrm{C}$ ambient temperature) & 600 Watt (at $50{ }^{\circ} \mathrm{C}$ ambient temperature) \\
\hline Impedance & $50 \Omega$ & $50 \Omega$ \\
\hline
\end{tabular}


Table 3: Radio BTS parameters used.

\begin{tabular}{|c|c|c|c|c|c|c|c|c|c|c|c|}
\hline $\begin{array}{l}\text { BTS } \\
\text { Type }\end{array}$ & $\begin{array}{l}\text { Site } \\
\text { code }\end{array}$ & $\begin{array}{c}\text { Site } \\
\text { Name }\end{array}$ & Wilaya & Région & Longitude & Latitude & Antenna & $\begin{array}{c}\text { HBA } \\
\text { Toit } \\
(\mathrm{m})\end{array}$ & $\begin{array}{c}\text { HBA } \\
\text { Sol } \\
(\mathrm{m})\end{array}$ & $\begin{array}{c}\text { Feed } \\
\text { Len } \\
(\mathrm{m})\end{array}$ & $\begin{array}{l}\text { Feed } \\
\text { Type }\end{array}$ \\
\hline 3900 & 23626 & Airoport & Annaba & Annaba & 7,8135 & 36,82081 & 739623 & & 18 & 22 & $7 / 8^{\prime \prime}$ \\
\hline 3900 & 23611 & $\begin{array}{c}\text { Sidi } \\
\text { Ammar }\end{array}$ & Annaba & Annaba & 7,72140 & 36,81419 & 739623 & 7 & 16 & 18 & $7 / 8 "$ \\
\hline 2206 & 23648 & $\begin{array}{c}\text { Sidi } \\
\text { Ammar } \\
\text { center }\end{array}$ & Annaba & Annaba & 7,71843 & 36,82214 & 739623 & 10 & 22 & 12 & $7 / 8 "$ \\
\hline 3900 & 23106 & $\begin{array}{c}\text { Annaba } \\
\text { center }\end{array}$ & Annaba & Annaba & 7,75967 & 36,90239 & $\begin{array}{c}\text { ATR } \\
451703\end{array}$ & $10 \mathrm{~m}$ & $22 \mathrm{~m}$ & $2 * 70$ & $7 / 8 "$ \\
\hline 2206 & 23627 & $\begin{array}{c}\text { Post } \\
\text { office } \\
\text { befor } \\
\text { harbor }\end{array}$ & Annaba & Annaba & 7,76256 & 36,89777 & 739634 & 4 & 29 & 26 & $7 / 8 "$ \\
\hline 2206 & 36694 & $\begin{array}{c}\text { Ben } \\
\text { Ammar }\end{array}$ & El Taref & Annaba & 7,81509 & 36,79176 & $\begin{array}{c}\text { ADU4548 } \\
01\end{array}$ & 10 & 19 & 15 & $7 / 8^{\prime \prime}$ \\
\hline
\end{tabular}

\section{Methodology}

We have relied in this work only on the $\mathrm{K}$ factor model. Knowing that several propagation models exist in the scientific literature on propagation.

\section{A. Propagation model K factors [13]}

The general form of the model $\mathrm{K}$ factor is given by the relation below:

$$
L_{p}=K_{1}+K_{2} \log (d)+K_{3} h_{m}+K_{4} \log \left(h_{m}\right)+K_{5} \log \left(h_{b}\right)+K_{6} \log \left(h_{b}\right) \log (d)+K_{7 \text { diff }}+K_{\text {clutter }}(1)
$$

The values of the parameters $K$ change according to the nature of the zone and the characteristics of the propagation environment of the cities, the table below gives values of $K$ and of the factor of attenuation of the congestion for an average city.

Table 4. Parameter values $K$.

\begin{tabular}{|c|c|c|c|c|c|c|c|c|}
\hline $\begin{array}{c}\text { Parameter } \\
\text { Name K }\end{array}$ & $K_{1}$ & $K_{2}$ & $K_{3}$ & $K_{4}$ & $K_{5}$ & $K_{6}$ & $K_{7 \text { diff }}$ & $K_{\text {clutter }}$ \\
\hline Value & 149 & 44.9 & -2.49 & 0.00 & -13.82 & -6.55 & -0.8 & 0 \\
\hline
\end{tabular}

Equation (1) can be written in this form:

$$
L_{p}=\left(K_{1}+K_{7 d i f f}+K_{\text {clutter }}\right)+K_{2} \log (d)+K_{3} h_{m}+K_{4} \log \left(h_{m}\right)+K_{5} \log \left(h_{b}\right)+K_{6} \log \left(h_{b}\right) \log (d)
$$

The:

$$
K_{1}^{\prime}=\left(K_{1}+K_{7 d i f f}+K_{\text {clutter }}\right)
$$

Equation (1) becomes:

$$
\begin{aligned}
& L_{p}=K_{1}^{\prime}+K_{2} \log (d)+K_{3} h_{m}+K_{4} \log \left(h_{m}\right)+K_{5} \log \left(h_{b}\right)+K_{6} \log \left(h_{b}\right) \log (d) \\
& L_{p}=\left(K_{1}^{\prime}+K_{3} h_{m}+K_{4} \log \left(h_{m}\right)+K_{5} \log \left(h_{b}\right)\right)+\left(k_{6} \log \left(h_{b}\right)+K_{2}\right) \log (d)
\end{aligned}
$$

Let:

$$
A=K_{1}^{\prime}+K_{3} h_{m}+K_{4} \log \left(h_{m}\right)+K_{5} \log \left(h_{b}\right)
$$

Equation (3) then becomes of the from :

$$
L_{p}=A+B \log (d)
$$

Equation (4) can also be put in vector form as follows:

$$
L_{p}=\left[\begin{array}{ll}
1 & \log (d)
\end{array}\right]\left[\begin{array}{l}
A \\
B
\end{array}\right]
$$


Riad Saidi, et al.

Equation (5) will be used hereinafter.

\section{B. Organizational chart}

The flow chart below generates the new propagation model using linear regression.

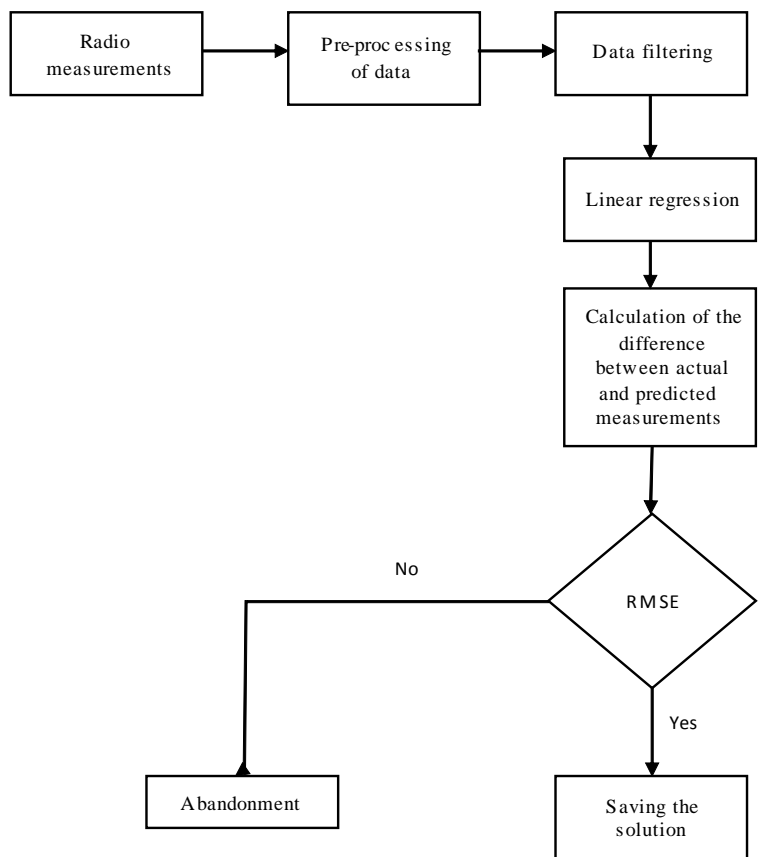

In this flowchart, the data was filtered according to the criteria below for the distance and signal strength received.

Table 5. Filter settings. [13][14]

\begin{tabular}{|c|c|}
\hline Minimum distance $(\mathrm{m})$ & 100 \\
\hline Maximum Distance $(\mathrm{m})$ & 10.000 \\
\hline $\begin{array}{c}\text { Minimum Received Power } \\
(\mathrm{dBm})\end{array}$ & -110 \\
\hline $\begin{array}{c}\text { Minimum Received Power } \\
(\mathrm{dBm})\end{array}$ & -40 \\
\hline
\end{tabular}

\section{Linear regression method}

This method is based on equation (3) presented previously. In the beginning, We will classify the parameters of equation (2) into two major groups [15]:

- The global adjustment parameters.

- Micro Adjustment Settings.

The global adjustment parameters here are $K_{1}$ and $K_{2}$, while the other coefficients are micro-adjustment parameters and thus, their default values in the standard model can be assumed to be constant. Starting from equation (5) already presented for one point of radio measurements for different distances d, we will obtain values of losses $L$, for $\mathrm{i}=1$ : $\mathrm{N}$ and (5) will become: 


$$
L_{i}=A+B \log \left(d_{i}\right)
$$

Where we can also write equation (6) in the following form:

$$
L_{i}=\left[\begin{array}{ll}
1 & \log \left(d_{i}\right)
\end{array}\right]\left[\begin{array}{l}
A \\
B
\end{array}\right]
$$

And for several measures, we will have:

$$
\left[\begin{array}{c}
L_{1} \\
L_{2} \\
\vdots \\
L_{N}
\end{array}\right]=\left[\begin{array}{cc}
1 & \log \left(d_{1}\right) \\
1 & \log \left(d_{2}\right. \\
\vdots & \vdots \\
1 & \log \left(d_{N}\right)
\end{array}\right]\left[\begin{array}{l}
A \\
B
\end{array}\right]
$$

Let :

$$
M=\left[\begin{array}{cc}
1 & \log \left(d_{1}\right) \\
1 & \log \left(d_{2}\right. \\
\vdots & \vdots \\
1 & \log \left(d_{N}\right)
\end{array}\right] \text { et } K=\left[\begin{array}{l}
A \\
B
\end{array}\right]
$$

From where can we get:

$$
L=M \cdot K
$$

We aim in our work to minimize the Euclidean distance between the values of the vectors $L$ which contains the prediction values and the values of the vector $L_{M}$ representing the measured values of the loss of propagation [16].

Is

$$
E=\left\|L_{M}-M \cdot K\right\|^{2}
$$

, The square error function.

To have the minimum searched distance it is necessary that:

$$
\frac{d E}{d K}=0
$$

From where:

$$
\begin{aligned}
& E=\|M . K\|^{2}-2(M K) L_{M}+\left\|L_{M}\right\|^{2} \text { Where the(.)Represents the scalar product. } \\
& E=K^{T} M^{T} M K-2 K^{T} M^{T} L_{M}+L_{M}^{T} L_{M}
\end{aligned}
$$

With $K^{T}$ is the transpose of $K$.

$$
\frac{d E}{d K}=0 \Rightarrow \frac{d\left(K^{T} M^{T} M K-2 K^{T} M^{T} L_{M}+L_{M}^{T} L_{M}\right)}{d K}=0
$$

Is :

$$
2 M^{T} M K-2 M^{T} L_{M}^{T}=0 \Rightarrow M^{T} M K=M^{T} L_{M}^{T}
$$

From this comes the solution $K^{*}$ :

$$
K^{*}=\left(M^{T} M\right)^{-1} M^{T} L_{M}=\left[\begin{array}{l}
A^{8} \\
B^{*}
\end{array}\right]
$$

This equation (11) translates the existence of a vector $K^{*}$ which would minimize the euclidean distance between the predicted and the measured values.

From this it follows that for constant $K_{3}, K_{4}, K_{5}, K_{6}$ we get:

$$
K_{1}^{*}=A^{*}-\left(K_{3} h_{m}+K_{4} \log \left(h_{m}\right)+K_{5} \log \left(h_{b}\right)\right)
$$




$$
K_{2}^{*}=B^{*}-K_{6} \log \left(h_{b}\right)
$$

\section{Results and discussions}

After applying the linear regression model to the data collected at the city of Annaba, we obtained the results below.

\section{A. The results by zone}

We had the curve below representing, the real measures, the Okumura Hata model, The model $K$ factors the result obtained by implementing the linear regression. The model will be seen as accurate if the RMSE between the prediction and measured values is less than $8 \mathrm{~dB}$; $($ RMSE <8dB)[17].

a-Zone Z1: Downtown of Annaba.

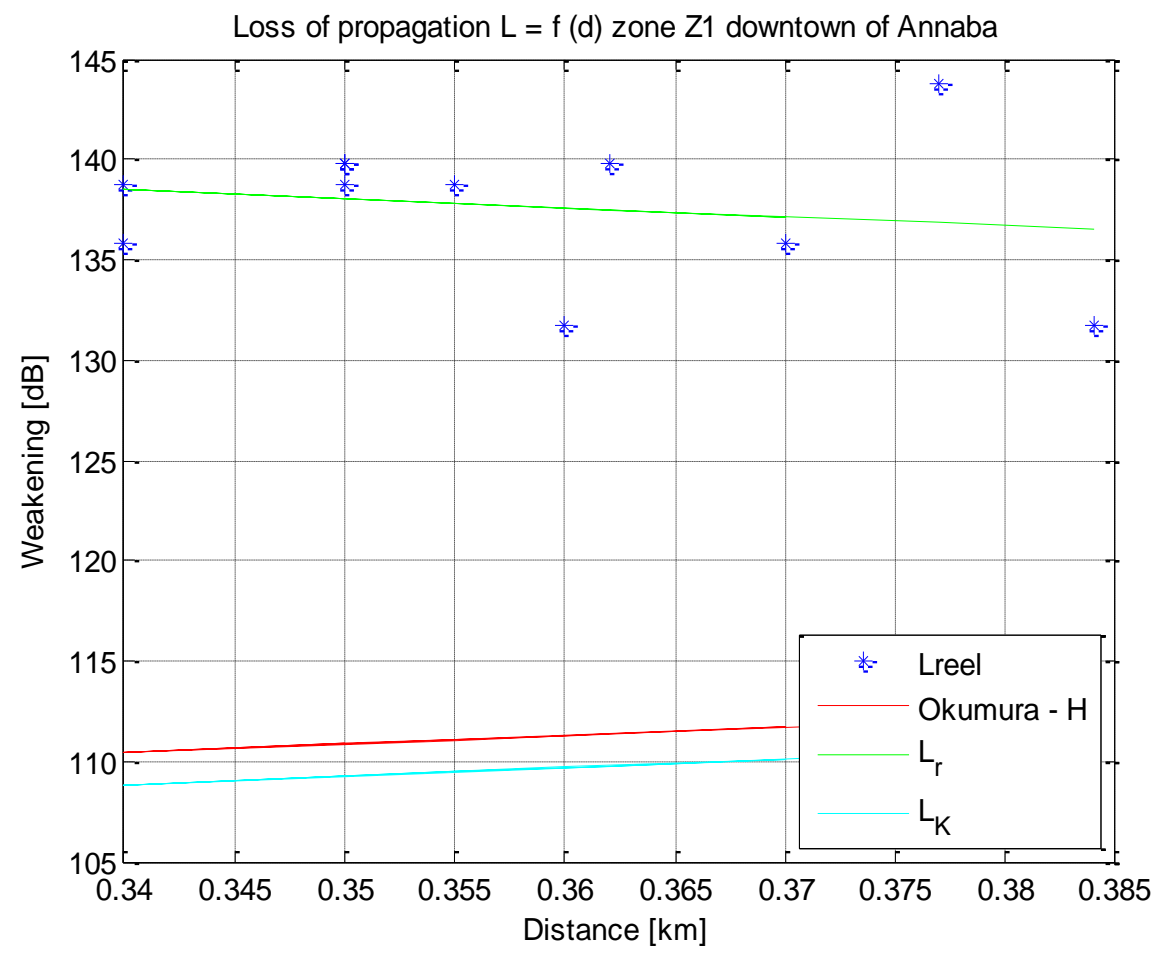

Figure 1. Weakening Real and predicted measurements of the downtown Annaba.

From this curve on the way the green regression model is closest to the reality of signal weakening at the city of Annaba. The table below gives the results obtained by the linear regression of different values of the coefficients $K$ as well as the RSME:

Table 6. Values of $K$ and RMSE coefficients obtained in downtwon of Annaba

\begin{tabular}{|c|c|c|c|c|c|c|c|c|}
\hline Zone & Results & $K_{1}$ & $K_{2}$ & $K_{3}$ & $K_{4}$ & $K_{5}$ & $K_{6}$ & RMSE \\
\hline \multirow{3}{*}{ Z1 } & K factors & 149 & 44,9 & $-2,49$ & 0 & $-13,82$ & $-6,55$ & 28.0960 \\
\cline { 2 - 9 } & $\begin{array}{c}\text { Okumura } \\
\text { Hata }\end{array}$ & 146,56 & 44,9 & 0 & 0 & $-13,82$ & $-6,55$ & 26.4858 \\
\cline { 2 - 9 } & Regression & 144.19 & -28.80 & $-2,49$ & 0 & $-13,82$ & $-6,55$ & 1.677 \\
\hline
\end{tabular}


According to the table, we clearly see that we have an RMSE $<8 \mathrm{~dB}$ for the model resulting from the regression, which confirms the credibility of the result, contrary to the $\mathrm{K}$ factor and Okumura Hata model.

b-Zone Z1: The post office after harbor.

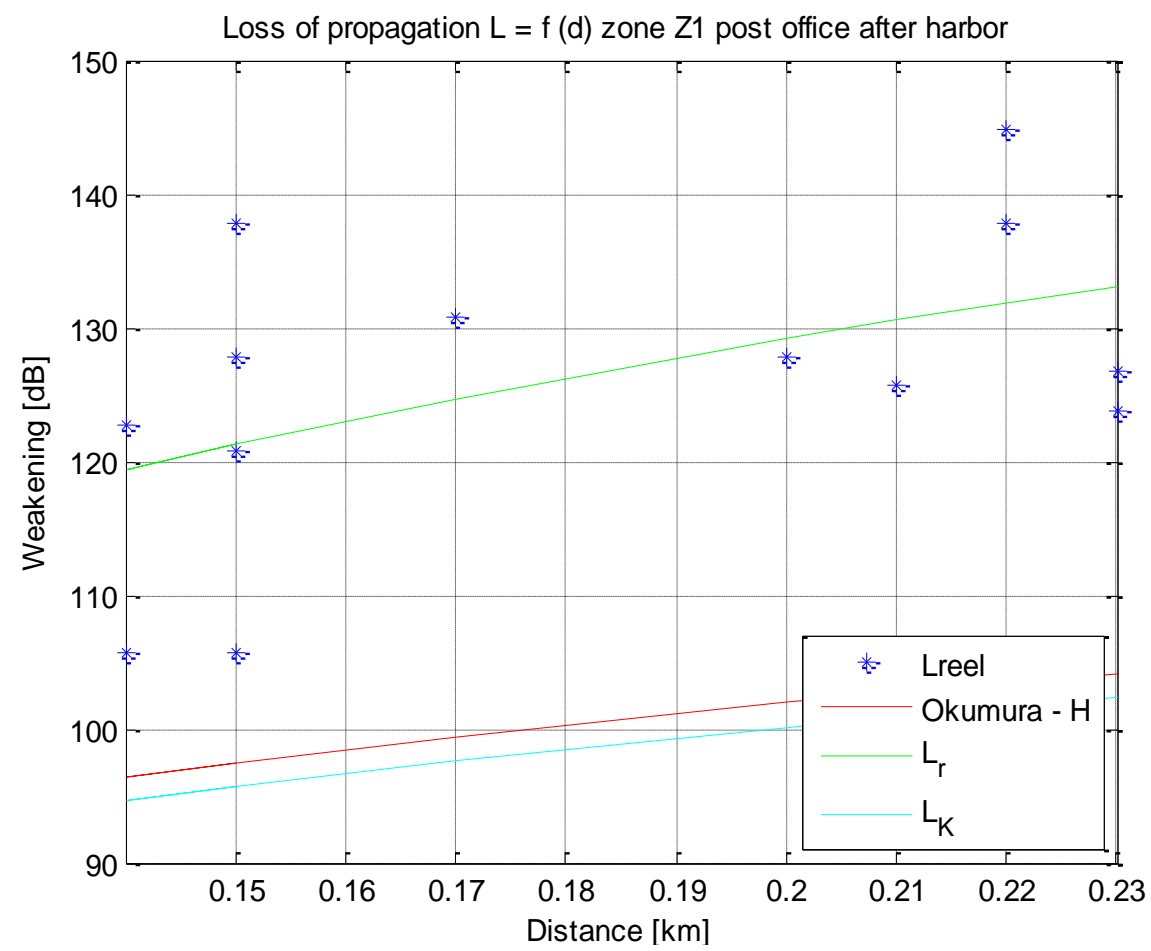

Figure 2. Weakening Real and predicted measurements of the post office before harbor.

From this curve in a clear way that the green regression model is closest to the reality of signal weakening at the downtown of Annaba. The table below gives the results obtained by the linear regression of different values of the coefficients K as well as the RSME:

Table 7. Values of the coefficients $K$ and RMSE obtained in the area of the post office before harbor.

\begin{tabular}{|c|c|c|c|c|c|c|c|c|}
\hline Zone & Results & $K_{1}$ & $K_{2}$ & $K_{3}$ & $K_{4}$ & $K_{5}$ & $K_{6}$ & RMSE \\
\hline \multirow{3}{*}{ Z1 } & K factors & 149 & 44,9 & $-2,49$ & 0 & $-13,82$ & $-6,55$ & 27.64 \\
\cline { 2 - 9 } & Okumura Hata & 146,56 & 44,9 & 0 & 0 & $-13,82$ & $-6,55$ & 25.8455 \\
\cline { 2 - 9 } & Regression & 197.52 & 72.77 & $-2,49$ & 0 & $-13,82$ & $-6,55$ & 4.4491 \\
\hline
\end{tabular}

This faith also is according to the table it is clear that we have an RMSE < $8 \mathrm{~dB}$ for the model resulting from the regression; which confirms the credibility of the result, unlike the $\mathrm{K}$ factor model and Okumura Hata. 
Riad Saidi, et al.

c-Zone Z2: Sidi Amar University.

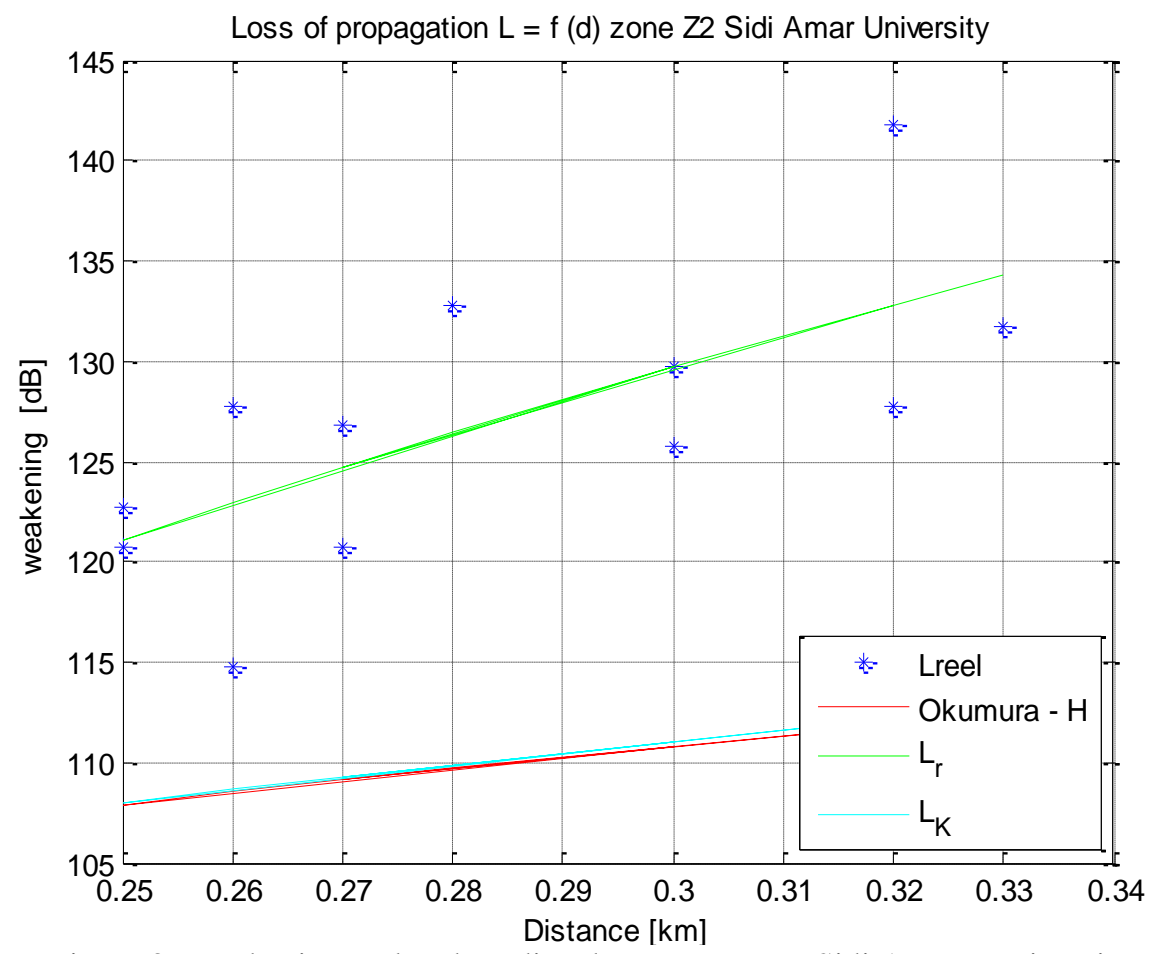

Figure 3. Weakening real and predicted measurements Sidi Ammar university.

From this curve on the way, the green regression model is closest to the reality of signal weakening at the downtown of Annaba. The table below gives the results obtained by the linear regression of different values of the coefficients $\mathrm{K}$ as well as the RSME:

Table 8. Values of K and RMSE coefficients obtained in Sidi Ammar university area.

\begin{tabular}{|c|c|c|c|c|c|c|c|c|}
\hline Zone & Results & $K_{1}$ & $K_{2}$ & $K_{3}$ & $K_{4}$ & $K_{5}$ & $K_{6}$ & RMSE \\
\hline \multirow{2}{*}{ Z2 } & K factors & 149 & 44,9 & $-2,49$ & 0 & $-13,82$ & $-6,55$ & 16.8562 \\
\cline { 2 - 8 } & $\begin{array}{c}\text { Okumura } \\
\text { Hata }\end{array}$ & 146,56 & 44,9 & 0 & 0 & $-13,82$ & $-6,55$ & 17.0430 \\
\cline { 2 - 9 } & Regression & 204.7 & 115.73 & $-2,49$ & 0 & $-13,82$ & $-6,55$ & 3.9707 \\
\hline
\end{tabular}

This faith also is according to the table it is clear that we have an RMSE < $8 \mathrm{~dB}$ for the model resulting from the regression; which confirms the credibility of the result, unlike the $\mathrm{K}$ factor model and Okumura Hata. 
d-Zone Z2: Sidi Ammar downtwon.

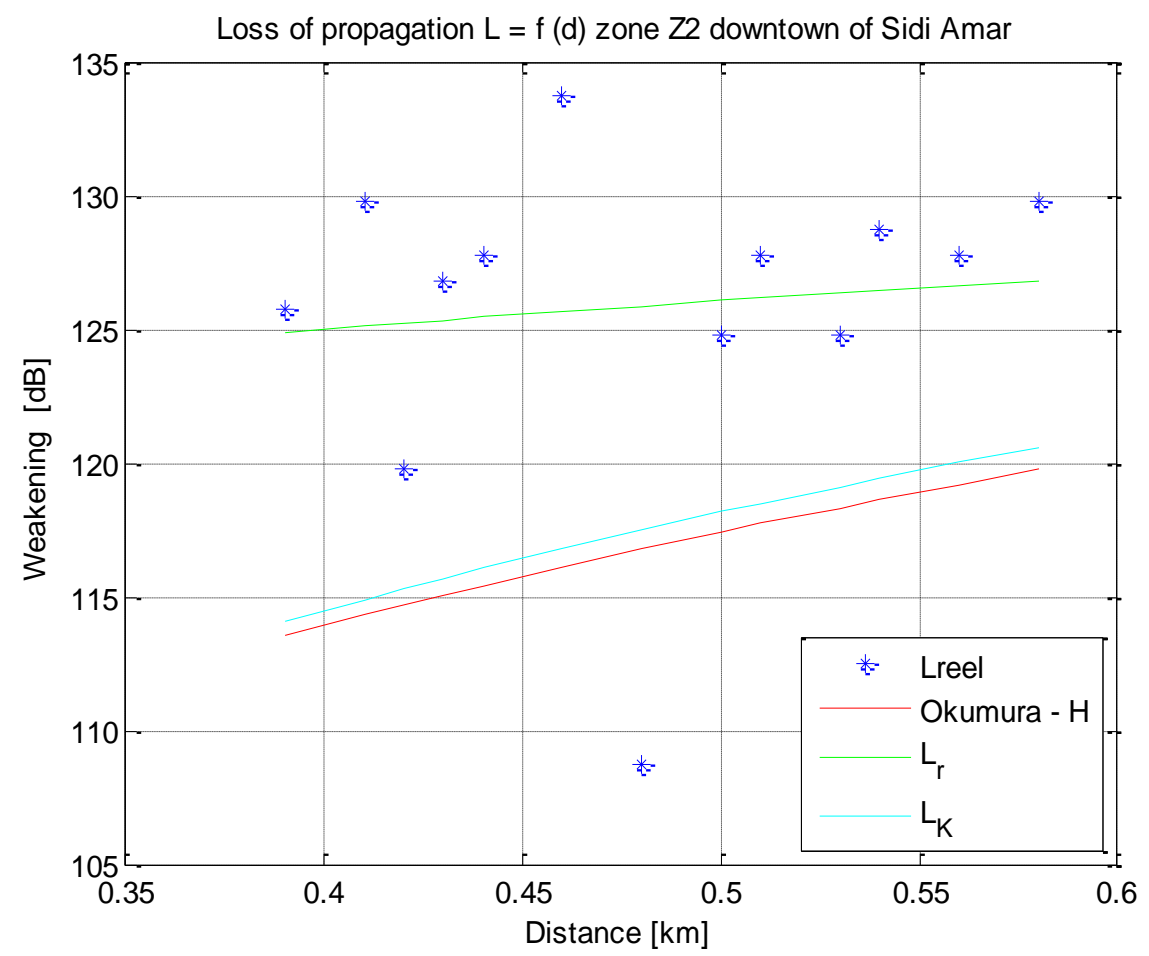

Figure 4. Weakening real and predicted measurements downtown of Sidi Ammar

According to this curve on the way, the green regression model is closest to the reality of the weakening of the signal at the city center of Sidi Ammar. The table below gives the results obtained by the linear regression of different values of the coefficients $\mathrm{K}$ as well as the RSME:

Table 9. Values of the coefficients K and RMSE obtained in the zone of the town center of sidi Ammar.

\begin{tabular}{|c|c|c|c|c|c|c|c|c|}
\hline Zone & Results & $K_{I}$ & $K_{2}$ & $K_{3}$ & $K_{4}$ & $K_{5}$ & $K_{6}$ & RMSE \\
\hline \multirow{3}{*}{ Z2 } & K factors & 149 & 44,9 & $-2,49$ & 0 & $-13,82$ & $-6,55$ & 8.4522 \\
\cline { 2 - 9 } & $\begin{array}{c}\text { Okumura } \\
\text { Hata }\end{array}$ & 146,56 & 44,9 & 0 & 0 & $-13,82$ & $-6,55$ & 9.1672 \\
\cline { 2 - 9 } & Regression & 148.9 & 18.29 & $-2,49$ & 0 & $-13,82$ & $-6,55$ & 8.8107 \\
\hline
\end{tabular}

This faith is according to the table it is clear that we have an RMSE> $8 \mathrm{~dB}$ for the model resulting from the regression; which explains the non-uniform and complex urban planning of Sidi Ammar, and in spite of this the result obtained is of better quality than the models of Okumura Hata and $\mathrm{K}$ factors. 
Riad Saidi, et al.

e-Zone Z3: Airport Rabeh BETATE Annaba.

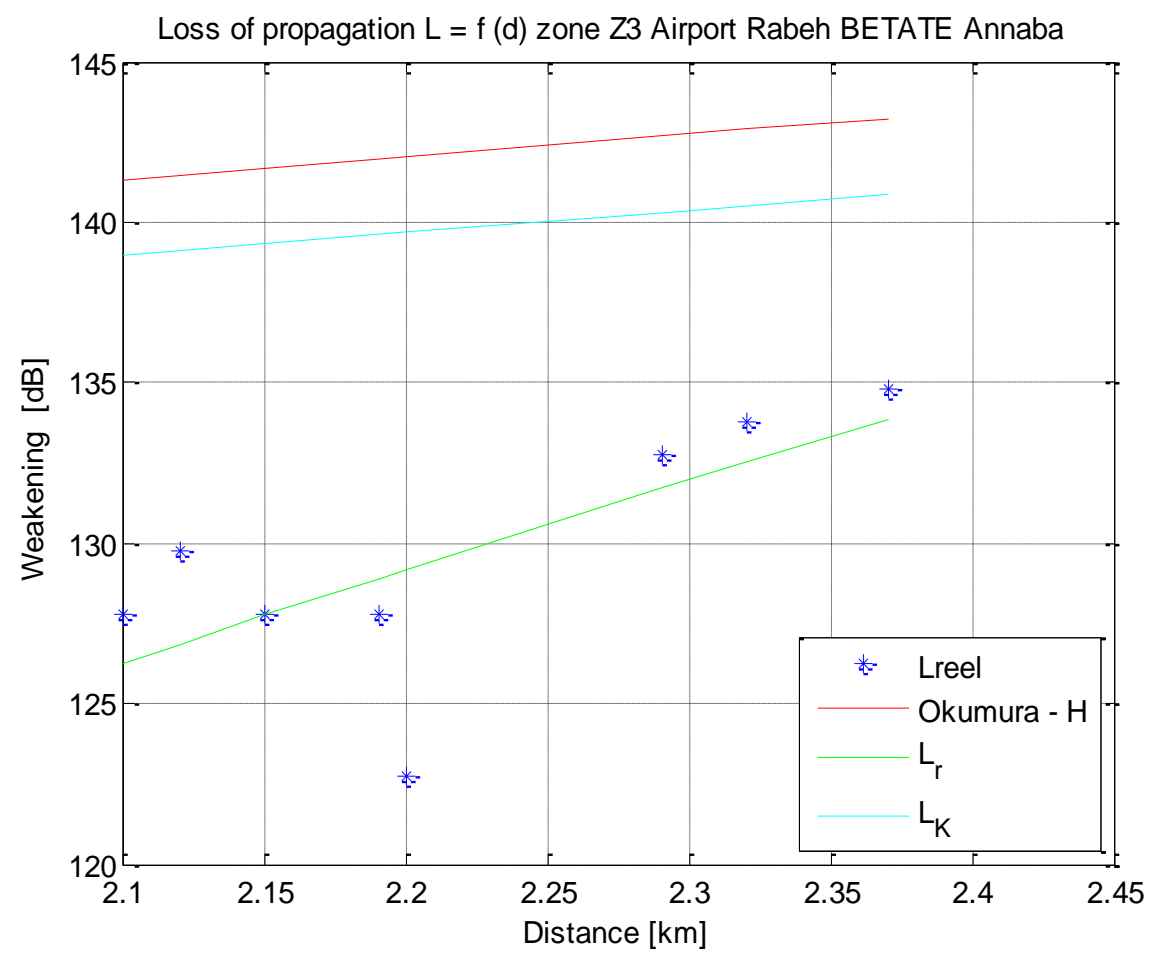

Figure 5. Weakening real and predicted measurements of airport Rabeh BETATE Annaba.

Following this curve on the way, the green regression model is closest to the reality of the signal weakening at the Rabeh BETATE airport zone in Annaba. The table below gives the results obtained by the linear regression of different values of the coefficients $\mathrm{K}$ as well as the RSME:

Table 10. Values of the coefficients K and RMSE obtained in airport Rabeh BETATE area.

\begin{tabular}{|c|c|c|c|c|c|c|c|c|}
\hline Zone & Résultats & $K_{I}$ & $K_{2}$ & $K_{3}$ & $K_{4}$ & $K_{5}$ & $K_{6}$ & RMSE \\
\hline \multirow{3}{*}{$Z 11$} & K facteurs & 149 & 44,9 & $-2,49$ & 0 & $-13,82$ & $-6,55$ & 10.1441 \\
\cline { 2 - 9 } & $\begin{array}{c}\text { Okumura } \\
\text { Hata }\end{array}$ & 146,56 & 44,9 & 0 & 0 & $-13,82$ & $-6,55$ & 12.5130 \\
\cline { 2 - 9 } & Régression & 101.42 & 153.26 & $-2,49$ & 0 & $-13,82$ & $-6,55$ & 6.5139 \\
\hline
\end{tabular}

This faith also is according to the table it is clear that we have an RMSE $<8 \mathrm{~dB}$ for the model resulting from the regression; Which also confirms the credibility of the result.

\section{B. Results Summary}

In this part, it was retained that the results giving an RMSE $<8 \mathrm{~dB}$, Namely those of zones Z1 (Downtown Annaba, La poste Avant Port), Z2(Sidi Ammar University), Z3(Airport Rabeh BETATE Annaba) Which gave us the mean vector recorded in the table below: 
Table 11. Evaluation of regression model

\begin{tabular}{|c|c|c|c|c|c|c|}
\hline Zone & $K_{1}$ & $K_{2}$ & $K_{3}$ & $K_{4}$ & $K_{5}$ & $K_{6}$ \\
\hline $\begin{array}{c}\text { Ville } \\
\text { d'Annaba }\end{array}$ & 571.77 & 78.24 & $-2,49$ & 0 & $-13,82$ & $-6,55$ \\
\hline
\end{tabular}

By evaluating the RMSE of this vector per zone we had the results indicated in Table 12.

Table 12. Evaluation RMSE of the model by zone.

\begin{tabular}{|c|c|c|c|c|c|}
\hline \multirow{2}{*}{ Zone } & \multicolumn{2}{|c|}{ Z1 } & \multicolumn{2}{c|}{ Z2 } & Z3 \\
\cline { 2 - 6 } & $\begin{array}{c}\text { Downtown } \\
\text { Annaba }\end{array}$ & $\begin{array}{c}\text { Poste } \\
\text { office } \\
\text { after } \\
\text { harbor }\end{array}$ & $\begin{array}{c}\text { Sidi Ammar } \\
\text { University }\end{array}$ & $\begin{array}{c}\text { Downtown } \\
\text { Sidi Ammar }\end{array}$ & $\begin{array}{c}\text { Airport Rabeh } \\
\text { BETATE Annaba }\end{array}$ \\
\hline RMSE & 1.677 & 4.4491 & 3.9707 & 8.8107 & 6.514 \\
\hline
\end{tabular}

The resulting final expression of our propagation model will be:

$$
L=571.77+78.24 \log (d)-2,49 h_{m}-13,82 \log \left(h_{\text {eff }}\right)-6,55 \log \left(h_{\text {eff }}\right) \log (d)
$$

With; $h_{\text {eff: }}$ The average height of buildings

\section{Conclusion}

These works, Present the results obtained by the implementation of the linear regression method on the data of radio measurements made in various zones of the city of Annaba. As a result, standard propagation models such as Okumura Hata and the $\mathrm{K}$ model are not adapted to our urban planning, So it is essential to optimize the said models to obtain models adapted to our environment. The linear regression method used allowed us to obtain a propagation model of the city of Annaba with an RMSE value between $1.677 \mathrm{~dB}$ and $6.514 \mathrm{~dB}$ while that of the OKUMURA HATA model varies from $9.167 \mathrm{~dB}$ to $25.845 \mathrm{~dB}$ And that of the model K factor of $8.452 \mathrm{~dB}$ and $27.64 \mathrm{~dB}$. We hold that the new model is more accurate and better represents the spread in the city of Annaba than the standardized models of OKUMURA HATA and K factor. The present aspect could be applied for the determination of the propagation model for each of the large cities Algeria in particular with the deployment of 4th generation mobile services.

\section{References}

[1]. Chhaya Dalela, et ail « tuning of Cost231 Hata modlc for radio wave propagation prédiction », Academv \& Indusrry Research Collaboration Center. May 2012.

[2]. Medcisis et Kajackas « the tuned Okumura Hata model in urban and rural zones at l.ituania at 160, 450, 900 and $1800 \mathrm{MHz}$ bands », Vehlcular Technology Conférence Proceedings. VTC 2000-Spring Tokyo. IF.BE 51 st Volume 3 Pages 1815 - 1818, 2000.

[3]. Prasad et al « tuning of COST-231 Hata model based on various data sets generated over vanous régions of India »,

[4]. Mardeni \&Priya et Ail, optimized COST-231 Hata model to predict path loss for suburban and open urban environments in the 2360-2390MHz, Progressin F.lectromagnetics Research C, Vol 13.91-106,2010 [6]. MingjingYang, et al «A l.inear Least Square Method of Propagation Model Tuning for 3G Radio Network Planning », Natural Computation, 2008. ICNC '08 Fourth International Conférence on Vol 5, pages 150 - 154. 2008 . 
[5]. MingjingYang; et al «A Linear Least Square Method of Propagation Model Tuning for 3G Radio Network Planning », Natural Computation, 2008. ICNC '08. Fourth International Conference on Vol. 5, pages 150 - 154, 2008.

[6]. Clicn, Y.H et Hsieh, Kl. « A Dual 1.east-Square Approach of Tuning Optimal Propagation Model for existing 3G Radio Network », Vehicular Technology Conférence, 2006. VTC 2006-Spring. IFFF 63rd Vol. 6, pages 2942 - 2946, 2006.

[7]. Simi I S et al «Minimax I.S algorithm for automatic propagation model tuning »,

[8]. Allam Mousa, Yousef Dama et AH «Optimizmg Outdoor Propagation Model based on Mcasurements for Multiple RF Cell ». Procceding of the 9th Télécommunications Forum (TFI.FOR 2001 ), Belgrade. Nov.2001

[9]. [9] D.D Eric Michel, T. Emmanuel. «Optimisation du modèle d'Okumura Hata par la régression linéaire. Application à la ville de Yaoundé au Cameroun », IOSR Journal of Electronics and Communication Engineering (IOSR-JECE) e-ISSN: 2278-2834,p- ISSN: 2278-8735.Volume 10, Issue 6, Ver. I (Nov - Dec .2015), PP 63-72

[10]. Famoriji and Olasoji «Development of a Radiowave Propagation Model for Hilly Areas», International Journal of Electronics Communication and Computer Engineering», ISSN (Online): 2249-071X, ISSN (Print): 2278-4209, Volume 4, Issue 2, pp. 536-540. (2013).

[11]. V.S. Abhayawardhana, I.J. Wassell, D. Crosby, M.P. Sellars, M.G. Brown «Comparison of empirical propagation path loss models for fixed wireless access systems» Vehicular Technology Conference, 2005. IEEE Date: 30 May-1 June 2005 Volume: 1, On page(s): 73- 77 Vol. 1

[12]. IIUAWF.I Technologies. 790-2200 MHz Base Station Antennas for Mobile Communications BTS3900\&BTS2206, et ATR451703 CDMA Product Documentation, pages $138-139$

[13]. HUAWEI Technologies, CW Test and Propagation Model Tuning Reportpage 7, 20 Mars 2014.

[14]. Standard Propagation Model Calibration guide, page 23, Avril 2004.

[15]. HUAWEI Technologies ; GSM RNP-RNO Radio Transmission Theory, pages 21-22, 2006.

[16]. R. Mardeni and K. F. Kwan «Optimization of hata propagation prediction model in suburban area in malaysia» Faculty of Engineering Multimedia University Jalan Multimedia, 63100 Cyberjaya, Selangor, Malaysia Progress In Electromagnetics Research C, Vol. 13, 91\{106, 2010.

[17]. A. Bhuvaneshwari, R. Hemalatha, T. Satyasavithri ; «Statistical Tuning of the Best suited Prediction Model for Measurements made in Hyderabad City of Southern India». Proceedings of the World Congress on Engineering and Computer Science 2013 Vol II WCECS 2013, San Francisco, USA pages 23-25 October, 2013. 


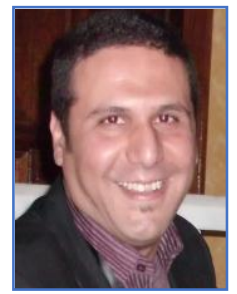

Riad SAIDI was born in Khenchela, Algeria, in 1973. He received the option engineering control in 1997 from the electronics institute of the University of Batna, Algeria. He had the communication magister of the electrical engineering department of Mohamed Kidder University of Biskra in 2010. He was a Research Associate at the Annaba Industrial Technology Research Unit of the welding and control center in Cheragua Alger, Algeria for two and a half years from 2011 to December 2013 as a Sensor Team Leader. Currently, he is a teacher and researcher in electrical engineering at the electrical engineering department of Larbi Tébessi University Tébessa, Algeria. He is a member of a research team in the laboratory of electrical engineering LABGET electrical engineering department of Larbi Tébessi University Tébessa, Algeria and also member of a research team in the laboratory in the LAAAS laboratory of University Mostefa Benboulaid, Batna2 - Algeria. His interests include telecommunications, mobile phone systems, as well as cryptography and network security.

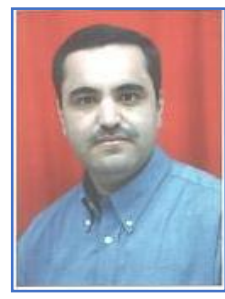

Lamir SAIDI received his Engineering Master degree from University of Constantine, Algeria, in 1991 and the Ph.D. degree from Savoie University, France, in 1996. Currently, he is Professor at the Electronics department, University Mostefa Benboulaid, Batna2 - Algeria and the Director of the LAAAS laboratory. His interests include Digital Signal Processing and Digital Motion Control.

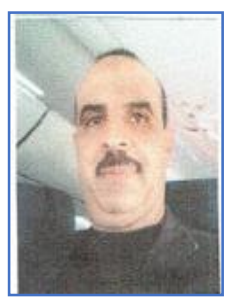

Zine el abidine REGAI was born in Batna, Algeria, in 1972. He received the option engineering control in 1997 from the electronics institute of the University of Batna, Algeria. He had the communication magister of the electrical engineering department of Mohamed Kidder University of Biskra in 2010. He was a airport manager at the Annaba Industrial. Currently. He is a member of a research team in the LAAAS Laboratory, University Mostefa Benboulaid Batna 2, and Batna, Algeria. His interests include telecommunications, mobile phone systems, as well as maintenance and use of the luggage scanner, programming and control by microcontrollers and electronic circuit's implementation by Proteus. 